\title{
Highly efficient inverted organic light-emitting diodes based on thermally activated delayed fluorescence
}

\author{
Xiaopeng Lv ${ }^{1,2}$, Hui Wang ${ }^{3}$, Lingqiang Meng ${ }^{2}$, Xiaofang $\mathrm{Wei}^{2}$, Yongzhen Chen ${ }^{2}, \mathrm{Xiangbin} \mathrm{Kong}^{2}$, \\ Jianjun Liu ${ }^{2}$, Jianxin Tang ${ }^{1}$, Pengfei Wang ${ }^{2}$ and Ying Wang ${ }^{2 *}$
}

\begin{abstract}
Green inverted organic light-emitting diodes (OLEDs) based on a thermally activated delayed fluorescent (TADF) emitter, 2-pheyl-4'-carbazole-9-H-thioxanthen-9-one-10,10-dioxide, with a cathode of indium tin oxide (ITO)/ZnO injecting electrons efficiently into the electron transporting layer of $\mathrm{Alq} 3$, are demonstrated for the first time. The insertion of 7-nm $\mathrm{Cs}_{2} \mathrm{CO}_{3}$ can further enhance the electron injection. The optimized device with $25-\mathrm{nm} \mathrm{ZnO}$ and $7-\mathrm{nm} \mathrm{Cs} \mathrm{CO}_{3}$ affords the highest performance of the inverted devices with a current efficiency of $28.1 \mathrm{~cd} \mathrm{~A}^{-1}$, a power efficiency of $16.1 \mathrm{~lm} \mathrm{~W}^{-1}$, and an external quantum efficiency of $9.8 \%$. The inverted OLEDs based on TADF emitters are competitive compared with conventional OLEDs because of their air-stable electrodes and TADF emitters, which enable simpler encapsulation.
\end{abstract}

Keywords: OLEDs, thermally activated delayed fluorescence, inverted OLEDs

Organic light-emitting diodes (OLEDs) have attracted increasing attention because of their advantages of low power consumption, light weight, fast response time, large viewing angle, high brightness, and mechanical flexibility [1-4]. Many efforts have been made to prepare high-performance OLEDs with excellent stability in the past two decades, and some products based on OLEDs have been introduced to the market [5-7]. Nevertheless, their intrinsic low environmental stability requires rigorous encapsulation to enhance their lifetime, which directly increases the final cost of the devices and thus limits the competiveness of OLEDs. Inverted-structured OLEDs have recently been reported as potential substitutes for conventional OLEDs [8-11]. In these devices, air-stable metals with high work functions were used as the anode, indium tin oxide (ITO) was used as the cathode, and air-stable metal-oxide layers were used as the electron-injection layers (EILs) and hole-injection layers (HILs). These metal oxides result in exceptional stability, mechanical and electrical robustness, low cost, transparency in the visible region, and solution-processable fabrication. Thus, the high stability of inverted OLEDs can be expected to fulfill the requirements of real applications. In addition, the inverted OLEDs have a bottom ITO cathode and can be directly connected to the drain electrode of a-Si thin film transistors, facilitating the fabrication of active matrix OLEDs for large-area displays. Although metal oxides can encapsulate the organic emitting layers from oxygen and moisture, the stability and performance of inverted OLEDs are unsatisfactory because of the limited stability of phosphorescent emitters and unbalanced hole and electron injection.

Thermally activated delayed fluorescent (TADF) emitters yield stable fluorescence with very high singlet yields, as these materials exhibit sufficiently small energy gaps between singlets and triplets to enable the up-conversion of triplet excitons to singlet excitons and then realize $100 \%$ internal quantum efficiency (IQE) of the singlet excitons formed by electric excitation. Versatile TADF emitters have been reported, including spiro-acridine, triazine, diphenyl sulfone derivatives, and thioxanthone (TX) derivatives [12-15]. OLEDs based on TADF emitters afford high

\footnotetext{
${ }^{1}$ Institute of Functional Nano \& Soft Materials (FUNSOM), Jiangsu Key Laboratory for Carbon-Based Functional Materials \& Devices, Soochow University, Suzhou 215123, China

${ }^{2}$ Key Laboratory of Photochemical Conversion and Optoelectronic Materials, Technical Institute of Physics and Chemistry, Chinese Academy of Sciences, Beijing 100190, China

${ }^{3}$ Key Laboratory of Synthetic and Natural Functional Molecule Chemistry of the Ministry of Education, College of Chemistry \& Materials Science, Northwest University, Xi'an 710069, China

* Corresponding author (email: wangy@mail.ipc.ac.cn)
} 
external quantum efficiencies (EQEs) up to $25 \%$, which is comparable to the best performance of OLEDs based on organic phosphorescent emitters [14]. Thus, TADF emitters are now regarded as the third generation of OLED emitters after fluorescent and phosphorescent emitters and will be the mainstream emitters of OLEDs. Both the improved stability and similar IQE of TADF emitters compared with that of phosphorescent emitters enable the potential application of TADF emitters in inverted OLEDs with high efficiency and excellent stability. However, no reports have been published on the construction and application of the inverted OLEDs based on TADF emitters, which inspired us to investigate the construction of high-efficiency inverted OLEDs based on TADF emitters. In 2014, our group reported on novel TADF emitters based on TX, and a high EQE of up to $21 \%$ was achieved for the OLEDs [15]. In this letter, we report the first inverted OLEDs based on TADF emitters. The devices consisted of an effective bottom cathode structure OLED with $\mathrm{ZnO}$ as the EIL and 2-pheyl-4'-carbazole-9-H-thioxanthen-9-one-10,10-dioxide (TXO-PhCz) as the TADF emitter, affording a maximum current efficiency of 28.1 $\mathrm{cd} \mathrm{A} \mathrm{A}^{-1}$, maximum power efficiency of $16.1 \mathrm{~lm} \mathrm{~W}^{-1}$, and maximum EQE up to $9.8 \%$.
The device structure of the inverted OLEDs and molecules and their energy levels are presented in Fig. 1. Efficient electron injection is an important issue in inverted OLEDs, because there is a large barrier between ITO and the electron transporting layer (ETL) due to the high work function of ITO up to 4.7-5.1 eV. ZnO films were used as the efficient and transparent EIL because of their wide band gap $\left(E_{\mathrm{g}} \sim 3.5 \mathrm{eV}\right)$, good electron transporting properties, and low work function. Moreover, $\mathrm{ZnO}$ films can be deposited using a solution-processed method at low temperature and exhibit excellent compatibility with plastic substrates, which is attractive for future plastic OLED displays with excellent flexibility. The devices were prepared as follows. Thin $\mathrm{ZnO}$ films were synthesized using a similar method to that described in previous reports and deposited onto pre-patterned ITO substrates using the spin-coating method [15]. Then, all the other layers, such as $\mathrm{Cs}_{2} \mathrm{CO}_{3}$, organic semiconducting layers, $\mathrm{MoO}_{3}$, and $\mathrm{Al}$, were deposited by sequential thermal evaporation under a base pressure of $4 \times 10^{-4} \mathrm{~Pa}$ without breaking the vacuum. The structure of the inverted OLEDs was as follows: $\mathrm{ITO} / \mathrm{ZnO}(x \mathrm{~nm}) / \mathrm{Cs}_{2} \mathrm{CO}_{3}(y \mathrm{~nm}) / \mathrm{Alq} 3(30$ $\mathrm{nm}) / 2,4,6$-tris(biphenyl-3-yl)-1,3,5-triazine (T2T) (10 $\mathrm{nm}$ )/TXO-PhCz:mCBP (10\% $30 \mathrm{~nm}$ )/1, 1-bis[(di-4-toly-
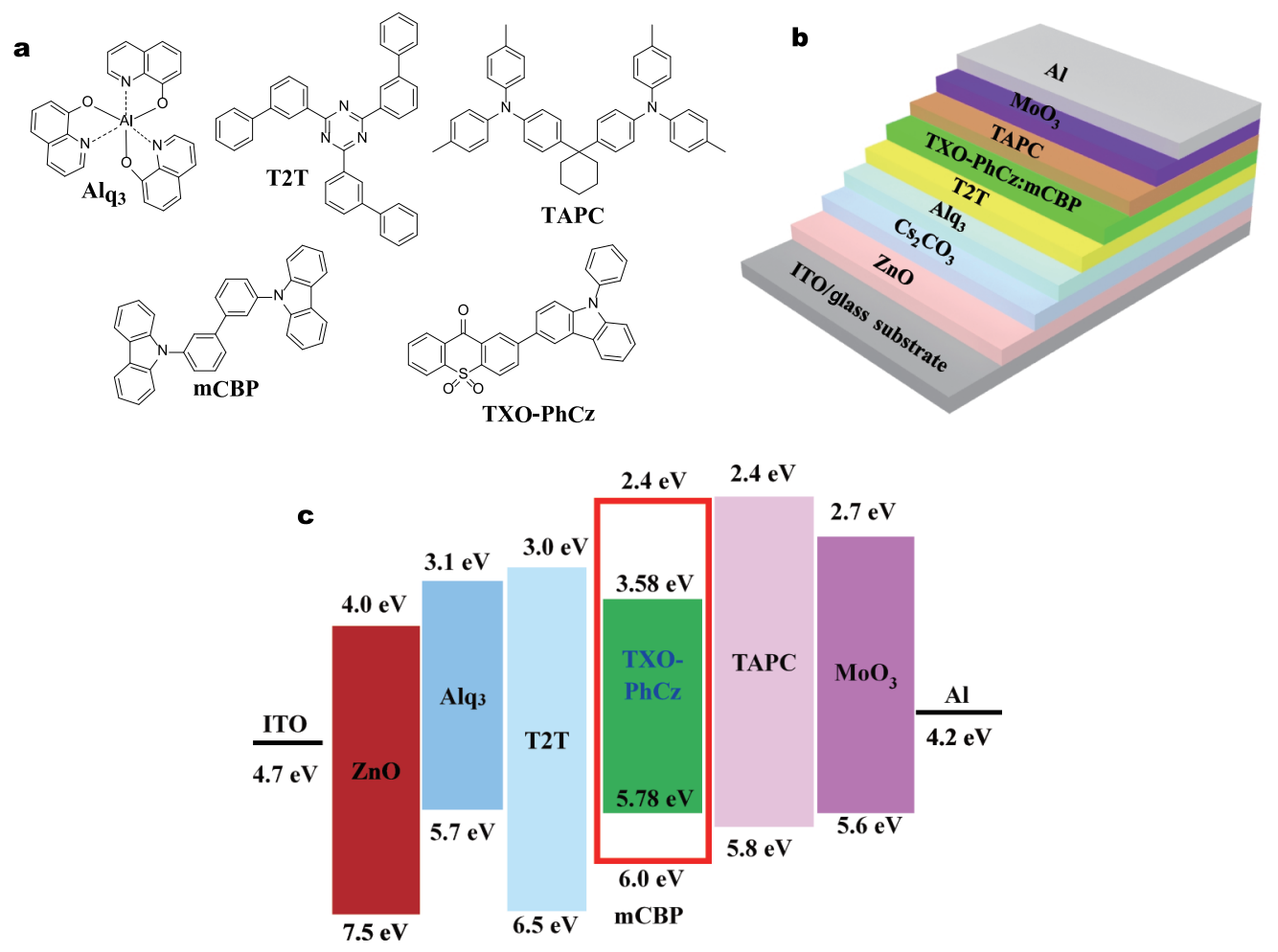

Figure 1 (a) Molecular structures of the organic semiconductors for the inverted OLEDs; (b) scheme of the inverted OLEDs; and (c) the energy levels of the materials involved in the inverted OLEDs. 
lamino)phenyl]cyclohexane (TAPC) $(50 \mathrm{~nm}) / \mathrm{MoO}_{3}(10$ $\mathrm{nm}) / \mathrm{Al}(100 \mathrm{~nm})(x=40,25$, and $20 \mathrm{~nm} ; y=0$ and $7 \mathrm{~nm})$. TAPC was used as the hole transporting layer (HTL), $\mathrm{MoO}_{3}$ was used as the HIL, Alq3 was used as the ETL, $\mathrm{Cs}_{2} \mathrm{CO}_{3}$ was used as the EIL, and T2T was used as the hole blocking layer (HBL).

The surface of $\mathrm{ZnO}$ films must be smooth to prevent short circuits between the metal oxide and $\mathrm{Al}$ anode. Thus, the morphology of the $\mathrm{ZnO}$ layers with different thicknesses was investigated using atomic force microscopy (AFM). As observed in Fig. 2, the ITO surface is covered by $\mathrm{ZnO}$ films, and all the $\mathrm{ZnO}$ films are homogeneous and flat with a low roughness. The root-mean-square (RMS) roughnesses are $3.75,3.30$, and $2.26 \mathrm{~nm}$ for the $\mathrm{ZnO}$ films with thicknesses of 40,25 , and $20 \mathrm{~nm}$, respectively. The RMS roughness decreases with increasing $\mathrm{ZnO}$ thickness. These roughness values are comparable and even lower than those of metal oxide films for inverted OLEDs, indicating that the $\mathrm{ZnO}$ films can be used for the EIL of OLEDs [16]. The transparencies of the $\mathrm{ZnO}$ films are also critical for the light out-coupling of OLEDs. The transparencies of ITO/ZnO films with different thicknesses are shown in Fig. 3. The transparency of the ITO/ZnO $(20 \mathrm{~nm})$ film is approximately $90 \%$ from 400 to $700 \mathrm{~nm}$, which is comparable to that of ITO/glass substrates. Upon increasing the thickness of the $\mathrm{ZnO}$ film, there is a small decrease in the transparency of the ITO/ZnO films from 450 to $600 \mathrm{~nm}$, and the transparency decreases from $90 \%$ of 20 $\mathrm{nm}$ to $87 \%$ of $40 \mathrm{~nm}$ at $500 \mathrm{~nm}$. Almost no decrease of the transparency can be observed, and the transmission curves almost overlap. These results indicate that the $\mathrm{ZnO}$ films exhibit excellent transparency, and the thickness of $\mathrm{ZnO}$ films negligibly affects the light out-coupling of the inverted OLEDs, facilitating the fabrication of inverted OLEDs with high performance.

Fig. 4 shows the current density-voltage $(J-V)$ and luminance-voltage $(L-V)$ characteristics of the devices, in which a thin layer of $\mathrm{Cs}_{2} \mathrm{CO}_{3}$ was placed between the $\mathrm{ZnO}$ and $\mathrm{Alq} 3$ to enhance the electron injection from $\mathrm{ZnO}$ to the organic layer. The insertion of the thin $\mathrm{Cs}_{2} \mathrm{CO}_{3}$ layer can remarkably enhance the electron injection from $\mathrm{ZnO}$ [17], leading to a higher current density compared with that of the device without the thin $\mathrm{Cs}_{2} \mathrm{CO}_{3}$ layer. After the insertion of the thin $\mathrm{Cs}_{2} \mathrm{CO}_{3}$ layer, the thickness of the $\mathrm{ZnO}$ film cannot remarkably affect the current densities because of the high carrier mobility of $\mathrm{ZnO}$ films, leading to a similar current density for all the devices with different $\mathrm{ZnO}$ thicknesses. Similarly, the insertion of the thin $\mathrm{ZnO}$ layer can remarkably reduce the turn-on voltage of the devices. The devices with the $40-\mathrm{nm} \mathrm{ZnO}$ film can be turned on at
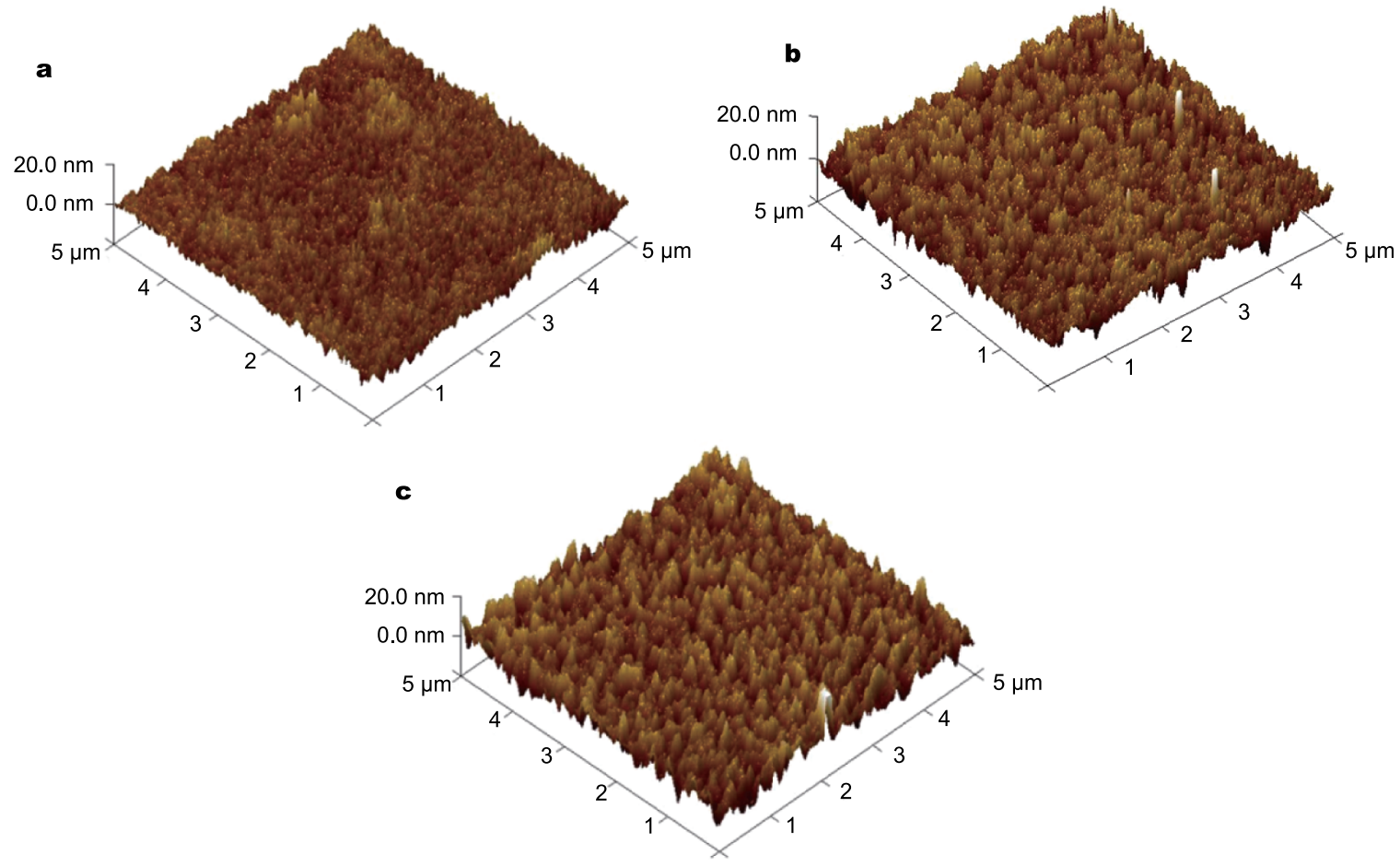

Figure 2 Three-dimensional topography of the surface of the $\mathrm{ZnO}$ films with different film thickness on ITO substrates: (a) 20; (b) 25; and (c) $40 \mathrm{~nm}$. The image size are $5 \mu \mathrm{m} \times 5 \mu \mathrm{m}$ and the RMS roughness is approximately $3 \mathrm{~nm}$. 


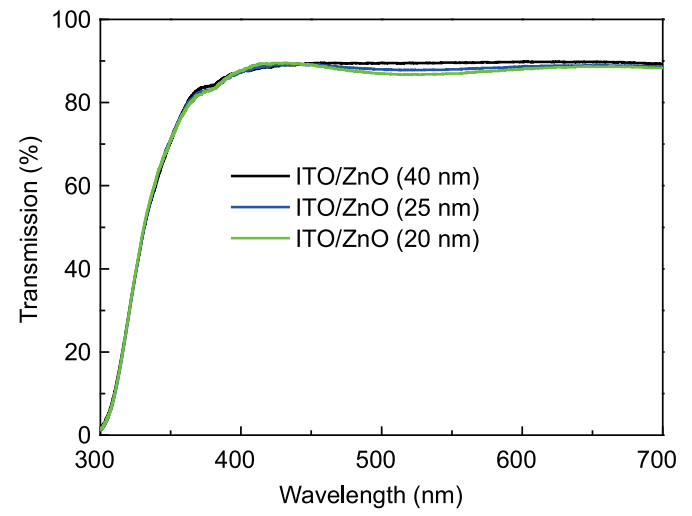

Figure 3 The transparencies of the ITO/ZnO films with different thickness $(20,25$ and $40 \mathrm{~nm})$.

7.25 V. The turn-on voltage was reduced to $6.25 \mathrm{~V}$ with the insertion of the 7-nm-thick $\mathrm{Cs}_{2} \mathrm{CO}_{3}$ layer. After the insertion of the thin $\mathrm{Cs}_{2} \mathrm{CO}_{3}$ layer, the lowest turn-on voltage of $4.9 \mathrm{~V}$ was obtained by the device with the $\mathrm{ZnO}$ film thickness of $25 \mathrm{~nm}$. These results can be attributed to the optimized recombination zone in the emitting layer, as the excitons can leak into the neighbor layer because of the high triplet/singlet energy of mCBP. For the device with the $25-\mathrm{nm} \mathrm{ZnO}$ layer, the maximum luminance, $L_{\max }$, was $8266 \mathrm{~cd} \mathrm{~m}^{-2}$ at $14.25 \mathrm{~V}$, and the driving voltage for 1000 $\mathrm{cd} \mathrm{m}^{-2}$ was only $11.5 \mathrm{~V}$, which is much lower than the values of reported inverted OLEDs. These results indicate that the $\mathrm{ZnO} / \mathrm{Cs}_{2} \mathrm{CO}_{3}$ layer can inject electrons very efficiently because of the improved energy-level matching. The turn-on voltages and driving voltages are still higher than those of phosphorescence OLEDs with optimal performance. These voltages can be further decreased by the development of new electron-injection materials from $\mathrm{ZnO}$ and organic layers [18]. Fig. 5 shows the light-emitting characteristics of the inverted OLEDs. A similar trend of turn-on voltages can also be observed for the device performance, including the current efficiency, power efficiency, and EQE. The devices without the 7-nm-thick $\mathrm{Cs}_{2} \mathrm{CO}_{3}$ layer emit green light with International Commission on Illumination (CIE) color coordinates of $(0.35,0.57)$ and exhibit a current efficiency of $2.1 \mathrm{~cd} \mathrm{~A}^{-1}$, a power efficiency of $0.6 \mathrm{~lm}$ $\mathrm{W}^{-1}$, and an EQE of $0.7 \%$. The performance of the device can be clearly enhanced with the insertion of a 7-nm-thick $\mathrm{Cs}_{2} \mathrm{CO}_{3}$ layer, affording a current efficiency of $6.2 \mathrm{~cd} \mathrm{~A}^{-1}$, a power efficiency of $1.8 \mathrm{~lm} \mathrm{~W} \mathrm{~W}^{-1}$, and an $\mathrm{EQE}$ of $1.8 \%$. The device with an optimized $\mathrm{ZnO}$ thickness of $25 \mathrm{~nm}$ exhibited the maximum performance, with a current efficiency of $28.1 \mathrm{~cd} \mathrm{~A}^{-1}$, a power efficiency of $16.1 \mathrm{~lm} \mathrm{~W}$, and an $\mathrm{EQE}$ of $9.8 \%$. This performance is among the best of those reported for OLEDs based on phosphorescent or fluorescent emitters $[7,9,13]$. Fig. 5d shows the electroluminescence (EL) of the devices. All the devices exhibited the typical EL spectrum of TXO-PhCz emission with CIE color coordinates of $(0.35,0.57)$. It has been reported that the thickness of the $\mathrm{ZnO}$ layers can induce optical interference effects, leading to the change in the spectra characteristics of the EL emission [16]. However, the EL spectra of all the devices overlapped, demonstrating the excellent transparency of the $\mathrm{ZnO}$ film. These findings coincide with the results above, demonstrating the excellent properties and potential application for the EIL for inverted OLEDs. To the best of our knowledge, these inverted OLEDs are the first to be based on the TADF emitter.

In summary, for the first time, we have demonstrated efficient green inverted OLEDs based on a TADF emitter, TXO-PhCz, with a transparent ITO/ZnO cathode. The device with a $25-\mathrm{nm} \mathrm{ZnO}$ film and $7-\mathrm{nm} \mathrm{Cs}_{2} \mathrm{CO}_{3}$ layer can be turned on at $4.9 \mathrm{~V}$ with maximum efficiencies of 28.1 $\mathrm{cd} \mathrm{A}^{-1}, 16.1 \mathrm{~lm} \mathrm{~W}^{-1}$, and $9.8 \%$. The thin $\mathrm{Cs}_{2} \mathrm{CO}_{3}$ layer can
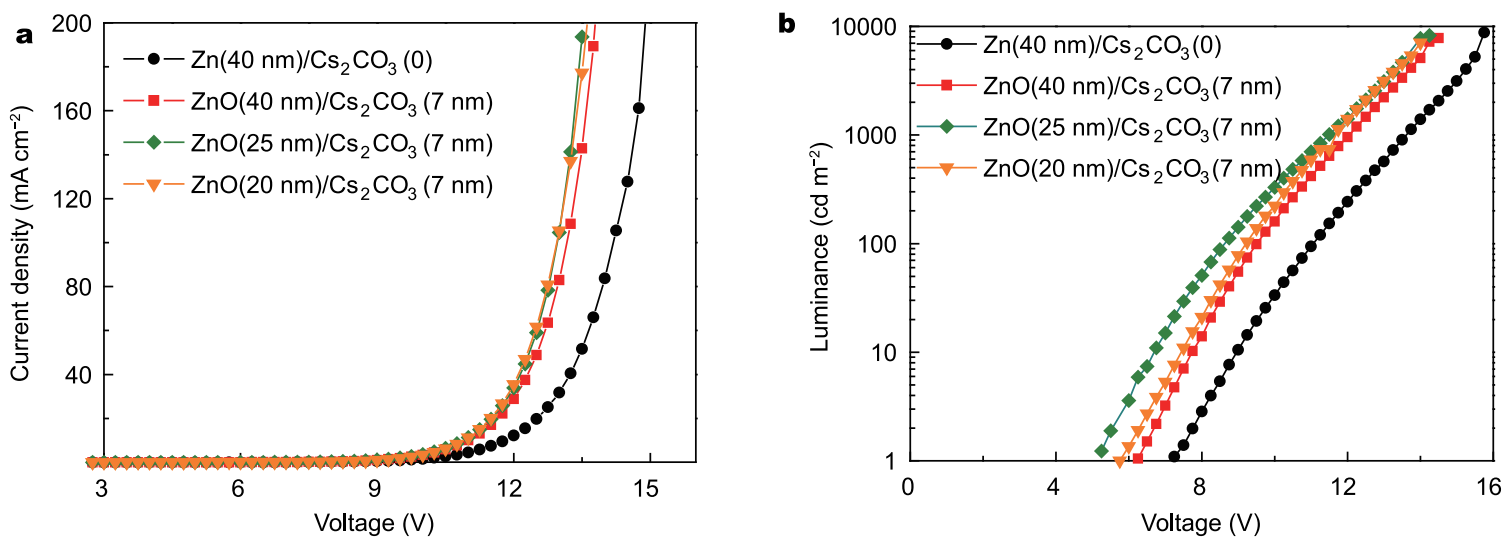

Figure 4 (a) The $J-V$; (b) $L-V$ characteristics of the devices fabricated with different $\mathrm{ZnO}$ layer thicknesses. 

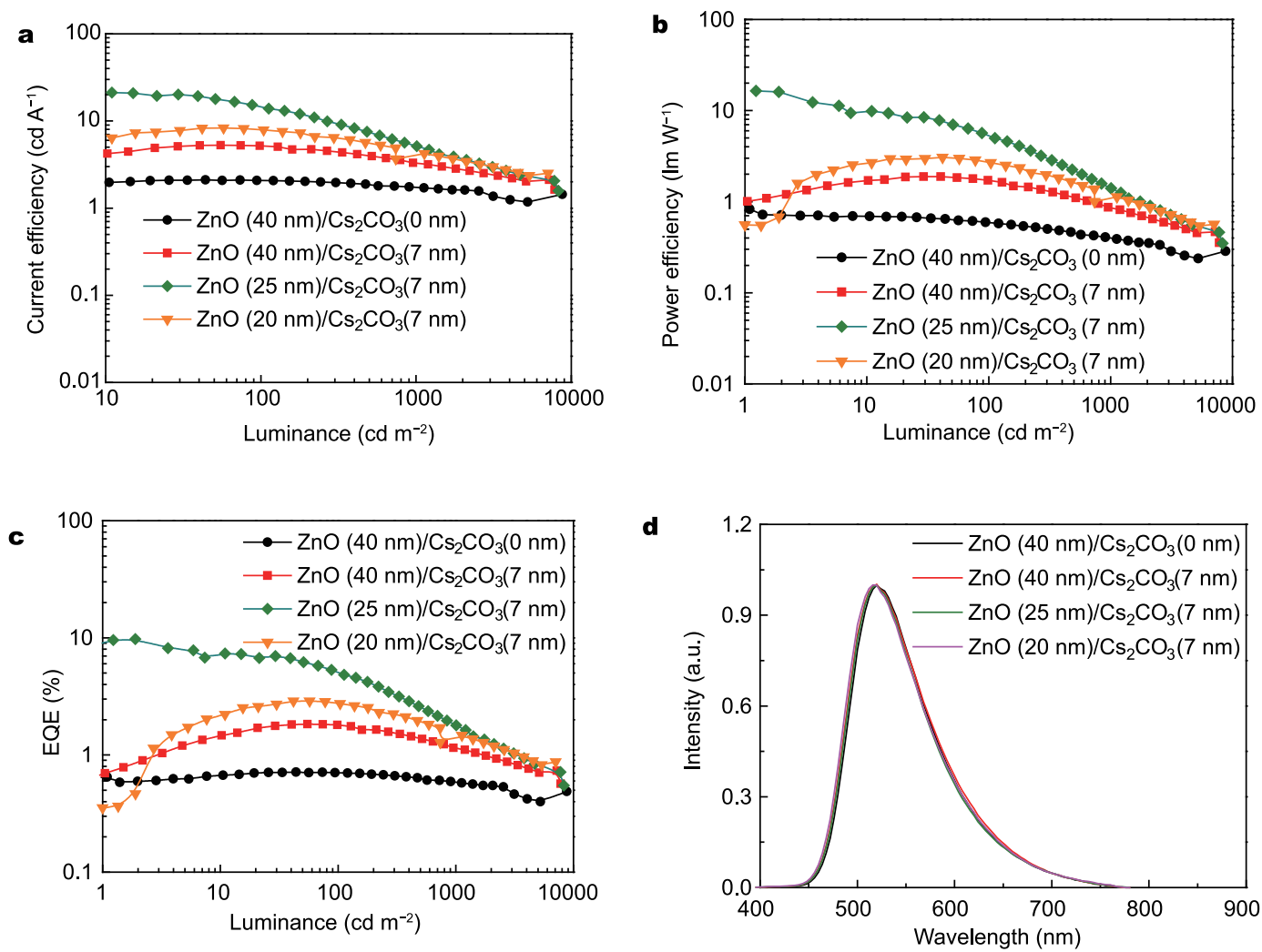

Figure 5 (a) The current efficiency-luminance characteristics; (b) the power efficiency-luminance characteristics; (c) EQE-luminance characteristics of the inverted OLEDs with different $\mathrm{ZnO}$ thicknesses. (d) Normalized EL spectra of the inverted OLEDs with different ZnO thicknesses at the same voltage of $8 \mathrm{~V}$.

form a thin interfacial EIL and HBL. These results demonstrate that the inverted OLEDs based on TADF emitters can be competitive compared with conventional OLEDs because of their air-stable electrodes and TADF emitters, which enable simpler encapsulation, paving new avenues for increasing the use of air-stable OLEDs with high performance.

Received 19 May 2016; accepted 26 May 2016; published online 23 June 2016

1 Tang CW, Vanslyke SA. Organic electroluminescent diodes. Appl Phys Lett, 1987, 51: 913

2 Tang CW, Vanslyke SA, Chen CH. Electroluminescence of doped organic thin films. J Appl Phys, 1989, 65: 3610

3 Friend RH, Gymer RW, Holmes AB, et al. Electroluminescence in conjugated polymers. Nature, 1999, 397: 121-128

4 Forrest SR, Baldo MA, O'brien DF, et al. Highly efficient phosphorescent emission from organic electroluminescent devices. Nature, 1998, 395: 151-154

5 Ying L, Ho CL, Wu H, et al. White polymer light-emitting devices for solid-state lighting: materials, devices, and recent progress. Adv Mater, 2014, 26: 2459-2473

6 Jansen-van vuuren RD, Armin A, Pandey AK, et al. Organic photodiodes: the future of full color detection and image sensing. Adv
Mater, 2016,

7 Seino Y, Inomata S, Sasabe $\mathrm{H}$, et al. High-performance green OLEDs using thermally activated delayed fluorescence with a power efficiency of over $100 \mathrm{~lm} \mathrm{~W}^{-1}$. Adv Mater, 2016, 28: 2638-2643

8 Sessolo M, Bolink HJ. Hybrid organic-inorganic light-emitting diodes. Adv Mater, 2011, 23: 1829-1845

9 Knauer KA, Najafabadi E, Haske W, et al. Inverted top-emitting blue electrophosphorescent organic light-emitting diodes with high current efficacy. Appl Phys Lett, 2012, 101: 103304

10 Zhong C, Liu S, Huang F, et al. Highly efficient electron injection from indium tin oxide/cross-linkable amino-functionalized polyfluorene interface in inverted organic light emitting devices. Chem Mater, 2011, 23: 4870-4876

11 Fukagawa $\mathrm{H}$, Morii $\mathrm{K}$, Hasegawa $\mathrm{M}$, et al. Highly efficient and air-stable inverted organic light-emitting diode composed of inert materials. Appl Phys Express, 2014, 7: 082104

12 Tao Y, Yuan K, Chen T, et al. Thermally activated delayed fluorescence materials towards the breakthrough of organoelectronics. Adv Mater, 2014, 26: 7931-7958

13 Uoyama H, Goushi K, Shizu K, et al. Highly efficient organic light-emitting diodes from delayed fluorescence. Nature, 2012, 492: 234-238

14 Lee DR, Kim M, Jeon SK, et al. Design strategy for 25\% external quantum efficiency in green and blue thermally activated delayed fluorescent devices. Adv Mater, 2015, 27: 5861-5867

15 Wang H, Xie L, Peng Q, et al. Novel thermally activated delayed 
fluorescence materials-thioxanthone derivatives and their applications for highly efficient OLEDs. Adv Mater, 2014, 26: 5198-5204 Lee H, Park I, Kwak J, et al. Improvement of electron injection in inverted bottom-emission blue phosphorescent organic light emitting diodes using zinc oxide nanoparticles. Appl Phys Lett, 2010, 96: 153306

17 Li Y, Zhang DQ, Duan L, et al. Elucidation of the electron injection mechanism of evaporated cesium carbonate cathode interlayer for organic light-emitting diodes. Appl Phys Lett, 2007, 90: 012119

18 Höfle S, Schienle A, Bruns M, et al. Enhanced electron injection into inverted polymer light-emitting diodes by combined solution-processed zinc oxide/polyethylenimine interlayers. Adv Mater, 2014, 26: 2750-2754

Acknowledgments This work was supported by the National Natural
Science Foundation of China (61420106002 and 51373189), the "Hundred Talents Program" of the Chinese Academy of Sciences, and the Start-up Fund of the Technical Institute of Physics and Chemistry, Chinese Academy of Sciences.

Author contributions $\quad \mathrm{Lv} \mathrm{X}$ and Wang $\mathrm{Y}$ designed the project, and the experiments. Lv X performed the experiments, and Lv $\mathrm{X}$ wrote the paper with support from Wang Y. All authors contributed to the general discussion.

Conflict of interest The authors declare that they have no conflict of interest.

Supplementary information Supplementary data are available in the online version of the paper.

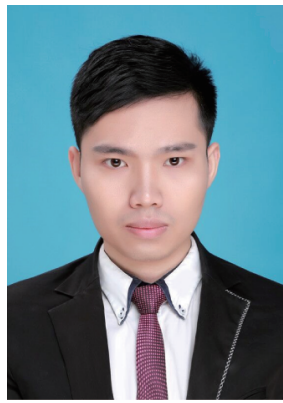

Xiaopeng Lv has been a master student at the Functional Nano \&Soft Materials Laboratory, Soochow University since 2013. His research is focused on the construction of high performance organic light-emitting devices.

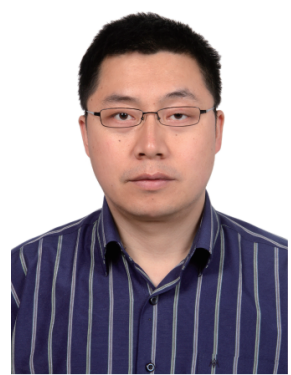

Ying Wang is a professor at the Key Laboratory of Photochemical Conversion and Optoelectronic Materials at the Technical Institute of Physics and Chemistry, Chinese Academy of Sciences. His research is focused on the photochemical and photophysical process of organic semiconductors and their application in organic electronics. He have authored and co-authored more than 40 international journal publications (including Nat Commun, J Am Chem Soc, Adv Mater, Phys Rev Lett, etc.) with more than 1400 citations.

\section{基于热激活延迟苂光材料的高效倒向有机发光二极管}

吕孝鹏 ${ }^{1,2}$, 王会 ${ }^{3}$, 孟令强 ${ }^{2}$, 魏晓芳 ${ }^{2}$, 陈永振 ${ }^{2}$, 孔祥憉 ${ }^{2}$, 刘建君 ${ }^{2}$, 唐建新 ${ }^{1}$, 汪鹏飞 $^{2}$, 王鹰 ${ }^{*}$

摘要 本论文首次报道了基于热激活延迟菼光材料 $\mathrm{TXO}-\mathrm{PhCz}$ 的倒置结构绿光有机电致发光器件. 器件以ITO/ZnO作为电子注入阴极, 提 高了电子向 $\mathrm{Alq} 3$ 层中的有效注入. $7 \mathrm{~nm}$ 的 $\mathrm{Cs}_{2} \mathrm{CO}_{3}$ 可以进一步提高电子的注入效率. 最优化器件以 $25-\mathrm{nm} \mathrm{ZnO}$ 和 $7-\mathrm{nm} \mathrm{Cs}_{2} \mathrm{CO}_{3}$ 层实现了电子 的有效注入, 器件显示出最佳性能, 器件的电流效率为 $28.1 \mathrm{~cd} \mathrm{~A}^{-1}$, 功率为 $16.1 \mathrm{~lm} \mathrm{~W}$, 外量子效率达 $9.8 \%$. 基于TADF发光材料的倒向OLEDs 器件由于其电极材料和发光材料的优异稳定性, 可以实现简单封装, 有望替代传统OLEDs. 